\title{
Article
}

\section{D image quantification of microbial iron chelators (siderophores) using diffusive equilibrium in thin films method}

Sandrine Le Houedec, Aubin Thibault de Chanvalon, Aurélia Mouret, Edouard Metzger, Patrick Launeau, Pierre Gaudin, and Thierry Lebeau

Anal. Chem., Just Accepted Manuscript • DOI: 10.1021/acs.analchem.8b04021 • Publication Date (Web): 14 Dec 2018

Downloaded from http://pubs.acs.org on December 15, 2018

\section{Just Accepted}

"Just Accepted" manuscripts have been peer-reviewed and accepted for publication. They are posted online prior to technical editing, formatting for publication and author proofing. The American Chemical Society provides "Just Accepted" as a service to the research community to expedite the dissemination of scientific material as soon as possible after acceptance. "Just Accepted" manuscripts appear in full in PDF format accompanied by an HTML abstract. "Just Accepted" manuscripts have been fully peer reviewed, but should not be considered the official version of record. They are citable by the Digital Object Identifier (DOI®). "Just Accepted" is an optional service offered to authors. Therefore, the "Just Accepted" Web site may not include all articles that will be published in the journal. After a manuscript is technically edited and formatted, it will be removed from the "Just Accepted" Web site and published as an ASAP article. Note that technical editing may introduce minor changes to the manuscript text and/or graphics which could affect content, and all legal disclaimers and ethical guidelines that apply to the journal pertain. ACS cannot be held responsible for errors or consequences arising from the use of information contained in these "Just Accepted" manuscripts. 


\title{
2D image quantification of microbial iron chelators
}

\section{(siderophores) using diffusive equilibrium in thin}

\section{films method}

Sandrine Le Houedec ${ }^{*}$, Aubin Thibault de Chanvalon ${ }^{1,3}$, Aurélia Mouret ${ }^{1}$, Edouard Metzgerl, Patrick Launeau², Pierre Gaudin'², Thierry Lebeau ${ }^{2}$.

1 UMR CNRS 6112 LPG-BIAF, Université d'Angers, 49045 Angers Cedex, France. (sandrine.lehouedec@univ-angers.fr, edouard.metzger@univ-angers.fr, aurelia.mouret@univangers.fr). * corresponding author.

2 UMR CNRS 6112 LPG Nantes, Université de Nantes, 44322 Nantes, France. (thierry.lebeau@univ-nantes.fr, patrick.launeau@univ-nantes.fr, pierre.gaudin@univ-nantes.fr)

3 University of Delaware, College of Earth, Ocean and Environment, Lewes, DE, USA. (aubintdc@udel.edu)

KEYWORDS: Siderophores, CAS assay, DET gels, plants, soil, iron

\begin{abstract}
Siderophores are natural metal chelating agents that strongly control the biogeochemical metal cycles such as Fe in the environment. This article describes a new methodology to detect and
\end{abstract}


quantify at the micromolar concentration the spatial distribution at millimetre scale of siderophores within the root's system. The "universal" CAS assay originally designed for bacterial siderophores detection and later designed for fungus was adapted here for diffusive equilibrium in thin film gel techniques (DET). The method was calibrated against the marketed desferrioxamine mesylate (DFOM) siderophore and applied with experiments performed with sunflower (Helianthus annuus) and wheat (Triticum aestivum) cultivated on free iron agar medium plates. We present here the first results with 2D images of the siderophores distribution in the vicinity of the root system of plants. With this technique we detected (i) the production of siderophores on bacteria inoculated (Pseudomonas fluorescens) environments, (ii) hotspots of natural iron binding ligands production up to $50 \mu \mathrm{M}$ in the wheat rhizosphere. The lower detection limit in our experiment was $2.5 \mu \mathrm{mol} / \mathrm{L}$. This new technique offers a unique opportunity to investigate the siderophore production in 2 dimensions in a wide range of applications from laboratory experiments to natural systems very likely using an in situ and non-destructive tool.

\section{Introduction}

Siderophores are organic iron-specific ligands with low molecular masses, which mainly sequester $\mathrm{Fe}^{3+}$ under depleted iron conditions ${ }^{1,2}$. Iron is essential for living organisms as it is involved in many metabolic pathways (i.e., respiration, oxygen metabolism, electron transfer). Under free iron-depleted environments, micro-organisms and plants are able to produce siderophores $^{3-8}$. Siderophores allow the recovery of iron from low bioaccessible sources such as the different Fe-bearing phases in soils, and its transport to the organisms ${ }^{9,10}$. Because iron availability is particularly low in environments with $\mathrm{pH}$ neutral and alkaline (i.e. carbonated soils and oceans), siderophores play an important role in the biogeochemical cycle of iron in these 
environments ${ }^{6,11-14}$. Recently, it was demonstrated that siderophores are also involved in the geochemical cycle of other nutrient metals such as $\mathrm{Cu}, \mathrm{Co}, \mathrm{Mn}, \mathrm{Mo}, \mathrm{Ni}^{15-20}$. Besides providing metals nutrients to organisms, siderophores enhance the biomass production in marine environments, i.e., plankton ${ }^{21}$, bacterial biomass ${ }^{22}$ and reduce plant pathogens in soils ${ }^{23-25}$. Siderophores can also contribute to metal bioremediation ${ }^{16,26-28}$. Thus, it would be wise to study the distribution of siderophores in environments to better understand both the patterns of production as well as the geochemical cycle of many metals in soils.

To describe the natural distribution of siderophores in soils is challenging because of (i) their low concentration $(\sim \mathrm{nM})^{29-31}$, (ii) the spatial heterogeneity of their distribution and (iii) the difficulty of accessing the root system without altering it. To overcome these problems the main procedure for analyzing them relies on the pre-concentration of soil pore-waters or seawater $29,32,33$, or on the use of hydroponic growth systems to sample the root's exudate ${ }^{34-38}$. For now, only one study has reported siderophore production in natural soils using non-destructive root exudate collectors ${ }^{39}$. While siderophores are more concentrated in the rhizosphere area as a result of the high density of microorganisms, some of which are able to produce siderophores, and/or due to the production of phytosiderophores by plants such as Poaceae, their quantification in the bulk soil remains a challenge due to lower siderophore production.

Here we aim to accurately detect and quantify the distribution of siderophore concentrations in the rhizosphere in two dimensions using an in situ and non-destructive sampling device. For this purpose, we developed a new method combining the colorimetric assay based on the Chrome Azurol S (CAS) colorimetric reagent that is a universal test to measure the Fe-chelating function of siderophores $^{1}$, with the diffusive equilibrium thin film technique (DET). Previously, the DET was used with the colorimetric method to obtain $2 \mathrm{D}$ distribution of elements such as iron and 
phosphates ${ }^{40-43}$. It was more recently improved with the use of the hyperspectral camera allowing a higher resolution and sensitivity as shown with iron/phosphates ${ }^{41}$ and nitrite/nitrate DET ${ }^{44}$. By combining hyperspectral imaging, the CAS method and DET technique, we developed a CASDET device that was tested in artificial media cultivated with wheat and sunflower. This device is composed of a sampling DET probe that is in contact with the studied medium/environment and a CAS reagent gel that is applied onto the DET probe after retrieval. Such approach gives it several advantages: (i) it allows passive in situ sampling of the growth medium pore-waters based on a diffusive equilibrium between a sampling medium device (polyacrylamide gel) and the natural pore-waters ${ }^{45}$. (ii) It prevents the CAS reagent from diffusing into the environment that could result in a loss of accuracy of the mapping and the contamination of the environment at the vicinity of the probe ${ }^{1,46}$. (iii) It better constrains matrix effects such as $\mathrm{pH}$ or ionic strength variability using a buffered reagent gel.

\section{Experimental Section}

Reagent gel preparation. The colorimetric reaction is based on the CAS assay ${ }^{1}$. The CAS reagent mixed with iron develops blue dyes (Fe-Dye). In presence of stronger ligand (L), such as siderophore, than CAS ( stability constant, $\mathrm{pH}=7, \operatorname{logK}\left(\mathrm{Fe}^{3+}\right)=15.6$ to $36.2{ }^{47}$, the iron will complex with the ligand and the CAS dye will return to its original orange/pink coloration according to the thermodynamic equilibrium. The following equation (Eq.1) shows the chemical principle of the reaction:

Fe-Dye (Blue) $+\mathrm{L} \leftarrow \rightarrow$ Fe-L + Dye (pink)

The CAS reagent was based on Andrews and Duckworth ${ }^{48}$ using $\mathrm{Fe}\left(\mathrm{NO}_{3}\right)_{3}$, Chrome Azurol-S (CAS), a surfactant (DDAPS) and the ammonium acetate buffer $\left(\mathrm{NH}_{4} \mathrm{ac}\right)$ and slightly modified 
to obtain the following concentrations: $\left[\mathrm{Fe}^{3+}\right]=20 \mu \mathrm{M}$; $[\mathrm{CAS}]=120 \mu \mathrm{M}$; $[\mathrm{DDAPS}]=3.8 \mathrm{mM}$; $\left[\mathrm{NH}_{4} \mathrm{ac}\right]=950 \mu \mathrm{M}$. The coloration of the CAS assay is known to be $\mathrm{pH}$ dependent ${ }^{49}$, the color varying from green in basic $\mathrm{pH}$ to pink/red under acidic $\mathrm{pH}$. Because the soil pore-waters can be variable in $\mathrm{pH}$ with depth, our CAS reagent was designed to be buffered under soil conditions (i.e from 5 to 9 , Figure $\mathrm{S} 1)$. The reagent gels are a $1 \mathrm{~mm}$ thick agarose gel $(1.5 \mathrm{wt} \%)$. Because this method is a colorimetric based technique, to achieve homogeneous coloration on such thin reagent gel is tremendously important. Preliminary results showed that diffusion of the reagent into the gel was highly heterogenous. In this context, the CAS assay was directly added to the melted agarose $\left(60^{\circ} \mathrm{C}\right)$ as done for bacterial or fungus cultures on agar plates ${ }^{48-50}$. The mixed solution was then slightly agitated and gently poured in a polycarbonate mold designed to make a $1 \mathrm{~mm}$ thick agarose gel. In order to congeal the agarose, the filled mold is left for at least $30 \mathrm{~min}$ at $5^{\circ} \mathrm{C}$.

In the reagent gel, as in solution, the dyes were formed by the CAS-Fe-DDAPS complex, and have a blue color and a maximum absorption peak at $622 \mathrm{~nm}$. In the presence of ligands such as siderophores the iron is chelated and thus the iron free CAS-DDAPS complex is released leading to a decrease in the absorption at $622 \mathrm{~nm}$.

Gel probe preparation and calibration. The probe is a $1 \mathrm{~mm}$ thick polyacrylamide gel stored in deionized water and prepared according to Jézéquel et al. ${ }^{40}$, adapted from Zhang and Davison $^{51}$. The gel was mounted in a $1 \mathrm{~mm}$ central depression on a polycarbonate plate and covered with a PVDF polyhydrophilic membrane $(0.2 \mu \mathrm{m}$, Durapore) taped on the plate.

For calibration, a $1 \mathrm{~mm}$ thick polyacrylamide gel was set between two pieces of polycarbonate plate tightly pressed together, one of which was designed to have 7 holes (schematic of the device detailed in Cesbron et al. 2014, supporting information ${ }^{41}$ ). These holes were used as 7 
wells, filled with $3.5 \mathrm{~mL}$ of standard solutions, covered by caps and left at least 1 hour to equilibrate. The standard solutions were made from desferrioxamine mesylate (DFOM, Sigma Aldrich) which has a stronger affinity $\left(\operatorname{logK}\left(\mathrm{Fe}^{3+}\right)=30.6^{52}\right)$ for iron III than the CAS molecule. The standard DFOM solutions were prepared to range from $2.5 \mu \mathrm{M}$ to $40 \mu \mathrm{M}$ and one well was filled with deionized water used as blank (DFOM.$=0 \mu \mathrm{mol} / \mathrm{L})$

The reagent gel was withdrawn from its mold and settled on a flat white support. Following this, the polyacrylamide gel was removed from its support and gently placed on the reagent gel using a moistened PVDF porous membrane. The two superimposed gels were covered by a thin transparent polyacetate film to avoid evaporation. The image acquisition was realized at least $1.5 \mathrm{~h}$ after the assemblage of the two gels.

Data acquisition and image treatment. The quantification of the siderophore concentration was entirely based on imagery technique. The assembled gels were scanned by a common commercial flatbed scanner (Canon Canoscan LiDE 600F) for the preliminary kinetics studies and by a hyperspectral camera (HySpex VNIR 1600) for quantitative analyses.

Conventional scanner imagery. The kinetic controls of the reaction were done using a DFOM solution at sufficient concentration $(30 \mu \mathrm{mol} / \mathrm{L})$ to be detected by a conventional office flatbed scanner. The images obtained were processed using ImageJ 1.31 open source software and were decomposed into primary colors RGB intensities, each being converted into a gray scale image. The intensity of colored zones was mainly in the red channel and therefore the image analyses for kinetics controls were based on the information held in this channel (Figure 2\&3).

Hyperspectral imagery. In order to quantify at high spatial resolution and sensibility the siderophore concentration, the image acquisitions of the two superimposed gels, after completion 
of the colorimetric reaction, were done with a hyperspectral camera HySpex VNIR 1600 camera with 160 channels. The camera was set up to scan samples with a spectral resolution of $4.5 \mathrm{~nm}$ and a sampling step of $3.7 \mathrm{~nm}$ covering a spectral range from 400 to $900 \mathrm{~nm}$ and a spatial resolution of $60 \times 60 \mu \mathrm{m}$ per pixel. To minimize evaporation, acquisition time was set to $8 \mathrm{~min}$. However, the quantification of the siderophore concentration based on this imagery technic is not direct and requires the following image treatment, performed here using the software ENVI

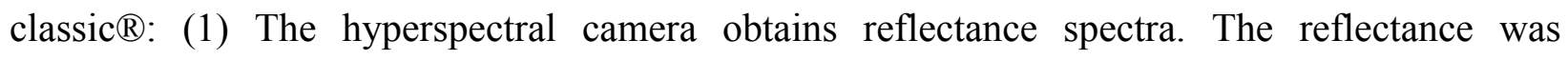
calculated by dividing each column of the analyzed image by the mean intensity of the light reflected from the white reference panel Spectralon ${ }^{\circledR}(\sim 99 \%$ reflectance in the $400-900 \mathrm{~nm}$ range) scanned alongside, in order to avoid the residual non-uniformity of the sensor. (2) In order to obtain the most accurate image as possible, it is necessary to remove the background noise that corresponds to erratic pixels (for example due to dust and air bubbles). This is a statistical treatment ("minimum noise fraction" function) retaining only the informative pixels. (3) This step is dedicated to the calculation of the transmittance spectrum. It is from these spectra that siderophore concentration can be calculated. Our gels formed a homogenous and compact layer having two plane-parallel faces deposited on a background (i.e. the white support). The reflected radiation results from (i) the inherent reflectance of our gels (measured with a black background) and (ii) the multiple background reflectance radiations which are the reflected signal from the non-black background, modified by the transmittance $\mathrm{T}$ of the gels ${ }^{53,54}$. Using a blank gel (i.e. without any coloration) the inherent reflectance was measured. This has a very low contribution (less than 5\%) to its apparent reflectance spectrum that can be set to 0 . This spectral property of our gel was found to be the same as for microphytobenthos biofilm previously studied with the same hyperspectral camera ${ }^{55-57}$. Therefore, the optical model used by those authors was applied 
on our gel images to calculate the transmittance signals from the measured reflectance signals (see equation 9 in Launeau et al., 2018). Therefore, a transfer function was used for converting the transmittance signal at $622 \mathrm{~nm}$ into concentration (Eq.2) obtained from the analysis of the calibration gel.

Plant Experiments. For validation, experiments were performed with plants cultivated in chemically controlled environments. Square Petri dishes $(120 \mathrm{~mm} \times 120 \mathrm{~mm} \times 10 \mathrm{~mm})$ were vertically filled with a mix of crumbled agar (9\%o) and glass balls $\left(\mathrm{SiO}_{2}, \varnothing=0.5 \mathrm{~mm}\right)$ in order to reproduce the natural structural heterogeneity of a soil. The seeding was done in a way that allows the opening of the Petri dishes without touching or moving the roots. A nutritive Hoagland solution was prepared without Fe to enhance the siderophore production and without $\mathrm{PO}_{4}{ }^{3-}$ as a precaution against its potential interference at high concentration with the reagents of the CAS assay ${ }^{1}$. However, $\mathrm{PO}_{4}{ }^{3-}$ is necessary for plant growth, and so a source of phosphate under a solid form (i.e., a layer of $\mathrm{CaPO}_{4}$ powder) was added at the bottom of each Petri dish. The possible $\mathrm{PO}_{4}{ }^{3-}$ interference will be detailed in a dedicated section later in the text.

Two Petri dishes were dedicated to the Triticum aestivum culture and two others to Helianthus annuus. Triticum aestivum was selected because of its potential as a Poacea to produce its own siderophores called phytosiderophores ${ }^{58-60}$. Helianthus annuus was used as a control plant because it does not produce phytosiderophores. For each experiment one of the two Petri dishes was inoculated with $7.6 \mathrm{~mL}$ of a $24 \mathrm{~h}$ culture of the bacteria Pseudomonas fluorescens (ATCC 17400 ) incubated in a Casamino acid medium (CAA, $\left.25^{\circ} \mathrm{C}\right)$. Pseudomonas fluorescens is well known to produce siderophores in free-iron depleted environment ${ }^{61-63}$. Before the inoculation, the cell suspension was concentrated to $1 / 5$ by centrifugation at $7690 \mathrm{~g} / 6 \mathrm{~min}$. The plants grew during 10 days before the deployment of the CAS-DET device. After 10 days, the Petri dishes 
were opened, and DET probes were put in close contact with the agar for 2 to $3 \mathrm{~h}$ in order to reach equilibrium between the gel probe and the agar solute. The successive steps of the CASDET device deployment are shown in a workflow schematic in Figure 1. Images were acquired the same way as for the calibration curve, with the hyperspectral camera after $1.5 \mathrm{~h}$ of contact between the gel probe and the reagent gel. We applied a false color filter on the image converted into concentration to enhance the visibility of the colorimetric variations.

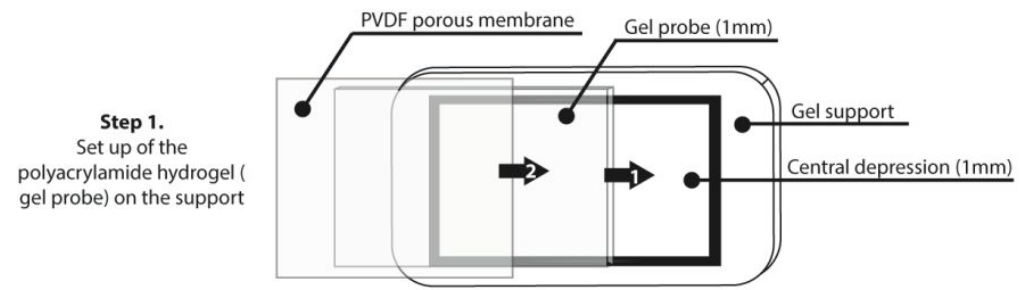




\section{Results and Discussion}

Equilibrium kinetics between gel probe and porous solution. The DET technique is based on the free diffusion of the pore-water compounds towards a hydrogel and chemical equilibrium between the gel and the external medium. Therefore, equilibrium time will depend on diffusion rates of the compounds and tortuosity of the porous media. To optimize the duration of that equilibrium phase, the kinetics of siderophore diffusion into the polyacrylamide gel was tested using a DFOM solution of $30 \mu \mathrm{mol} / \mathrm{L}$. Diffusion time ranged from $30 \mathrm{~min}$ to $8 \mathrm{~h} 30$ (Figure 2). As shown by the obtained profiles, the intensity of the signal is stable from $1 \mathrm{~h}$ to $8 \mathrm{~h} 30$ of equilibration and the lateral diffusion remains negligible as it does not exceed $2 \mathrm{~mm}$ of diameter enlargement after $8 \mathrm{~h}$ of equilibration. Therefore, we recommend an equilibration time between 2 and 3 hours between the probe and the environment as applied for our plant experiments in order to enlarge the range of temperature conditions and siderophores that might have different diffusion coefficients.
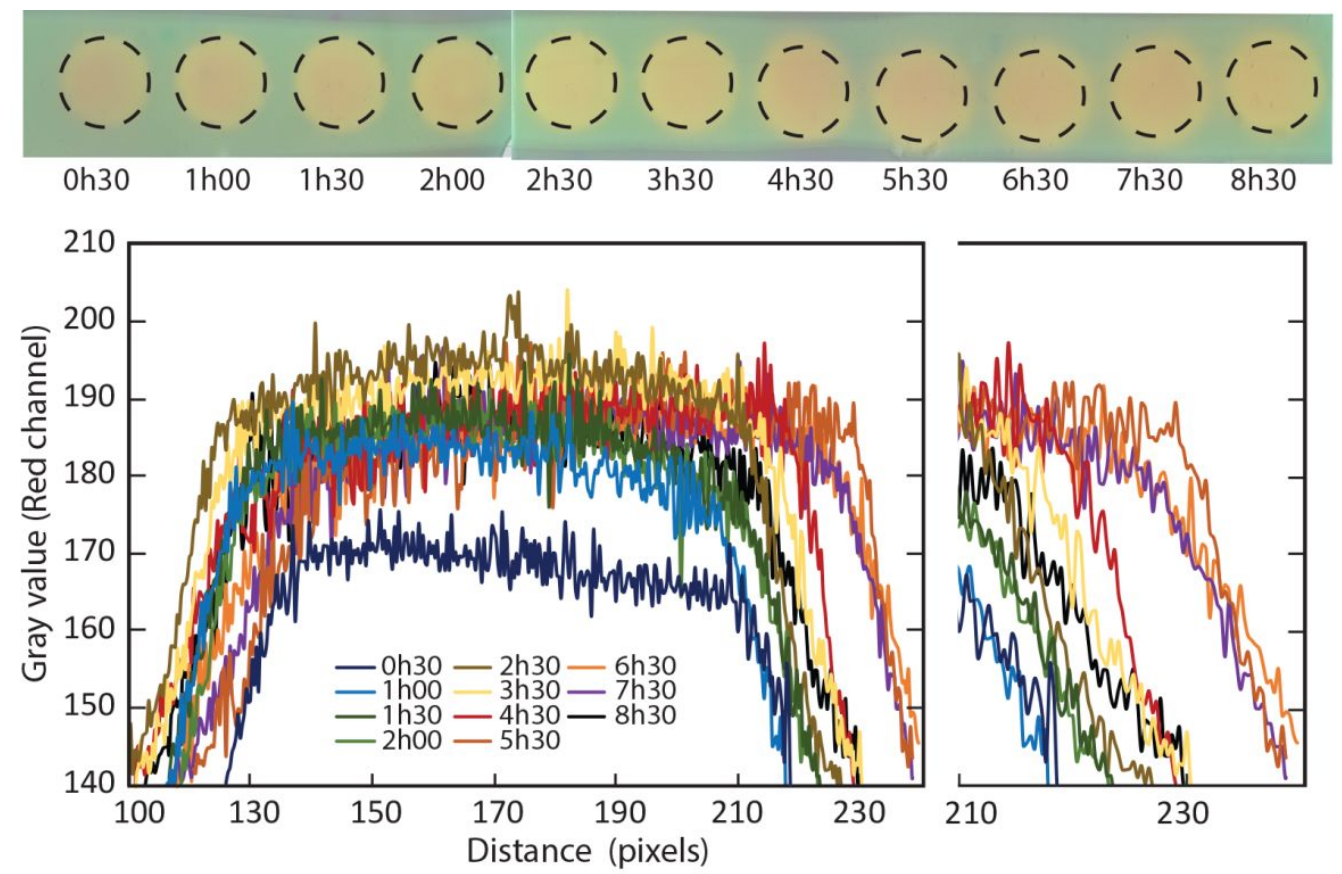
Figure 2: Equilibrium kinetics between DFOM and the polyacrylamide gel probe. The gel image was reported on the top with the time of equilibration between the DFOM solution $(30 \mu \mathrm{mol} / \mathrm{L})$ and the gel probe. The image was taken $1 \mathrm{~h}$ after contact with the reagent gel. The dashed circles correspond to the well edges. The profiles presented here were obtained from the red channel analysis of the image through a cross section of each one of the wells. The right part of the graph is a zoom of the well's edge profiles.

Reaction kinetics of DFOM with the reagent gel. The optimal staining time starting after contact between the polyacrylamide gel and the reagent gel depends on the completeness of color development. The kinetics of the colorimetric reaction depends on the diffusional equilibrium between the 2 gels and the diffusional relaxation, which alters the fidelity of distribution of the measured dissolved species. For this monitoring, we used a concentrated solution of siderophore $(\mathrm{DFOM}=30 \mu \mathrm{mol} / \mathrm{L})$. The completion of the reaction between the reagent gel and the gel probe has taken $1.5 \mathrm{~h}$ (Figure $3 \mathrm{~b}, \mathrm{c}$ ) then the signal remained stable in the following 3h (Figure 3c).

a

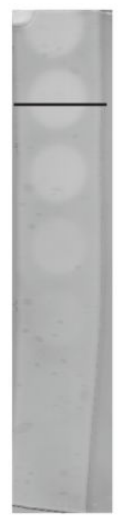

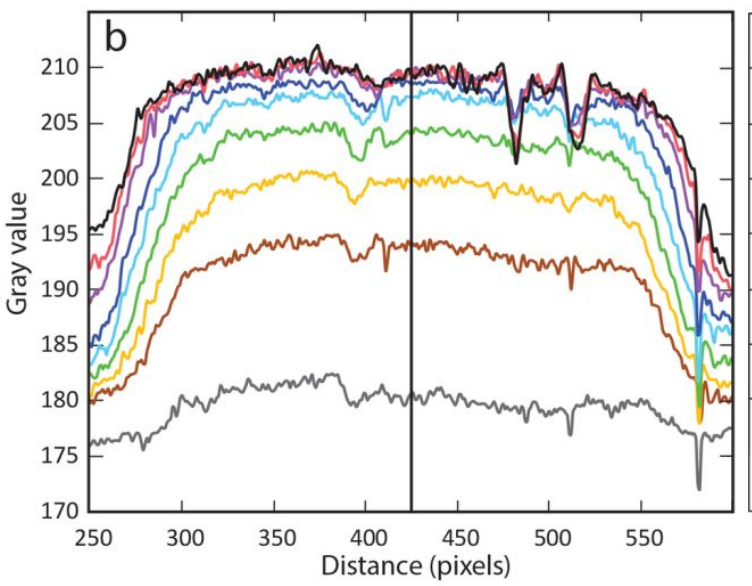

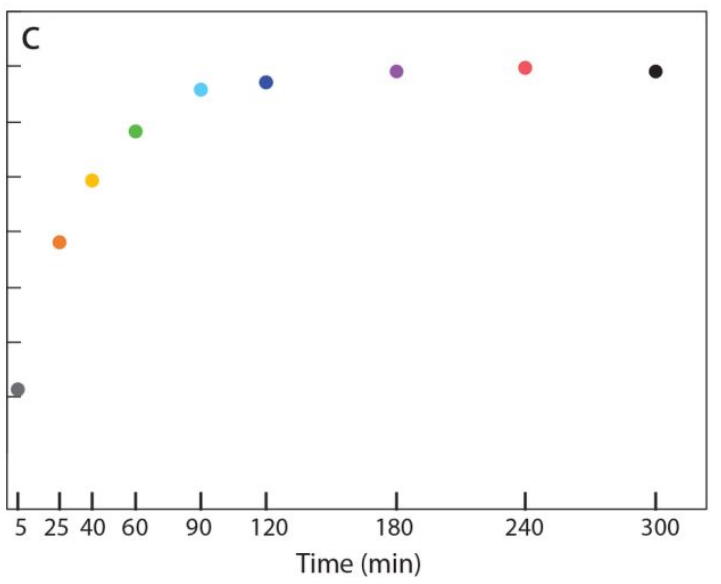

Figure 3: Reaction kinetics of DFOM with the reagent gel. a. calibration gel, DFOM between 0 to $40 \mu \mathrm{mol} / \mathrm{L}$ from bottom to top $(0 ; 2.5 ; 5 ; 10 ; 20 ; 30 ; 40 \mu \mathrm{mol} / \mathrm{L})$. The black vertical line 
represents the cross section presented in Figure $3 b$. b. DFOM profiles $(30 \mu \mathrm{mol} / \mathrm{L})$ through time after contact between the calibration gel and the reagent gel, converted into gray scale from the red channel filter (Image $J$ software treatment). The black line represents the values used to obtain the time profile presented on Figure 3c. c. Gray scale values' evolution with time. Dot colors correspond to profile colors from Figure $3 \mathrm{~b}$.

The good superimposition of the profiles at the boarders of standard wells (Figure $3 b$ ) indicates that the lateral diffusion of the iron free CAS-DDAPS complex is minimal after contact with the reagent gel. Consequently, the relaxation effect is negligible during the colorimetric reaction if the image acquisition is done within a temporal window of $5 \mathrm{~h}$ after contact between probe and reagent gels.

Calibration Curve. Initially, the image treatment method from hyperspectral measurements was set up on gels with standard solutions (with DFOM at 2.5 up to $40 \mu \mathrm{mol} / \mathrm{L}$ and deionized water for control) and compiled in Figure 4. A region of interest (Figure 4a) was selected on the image of the assembled gels for the six DFOM standards and the control resulting in a mean reflectance spectrum for each concentration (Figure 4b). Using the image treatment previously detailed, reflectance spectra are converted into transmittance spectra (Figure 4c). A relation between the maximum transmittance signal at $622 \mathrm{~nm}$ and the siderophore concentration (Figure 4d) was established (Eq.2, $\left.\mathrm{r}^{2}=0.995\right)$ such as:

$\mathrm{Cs}=205.12^{*} \mathrm{~T}-127.55$

Cs: Concentration siderophore

$\mathrm{T}:$ transmittance signal at $622 \mathrm{~nm}$. 

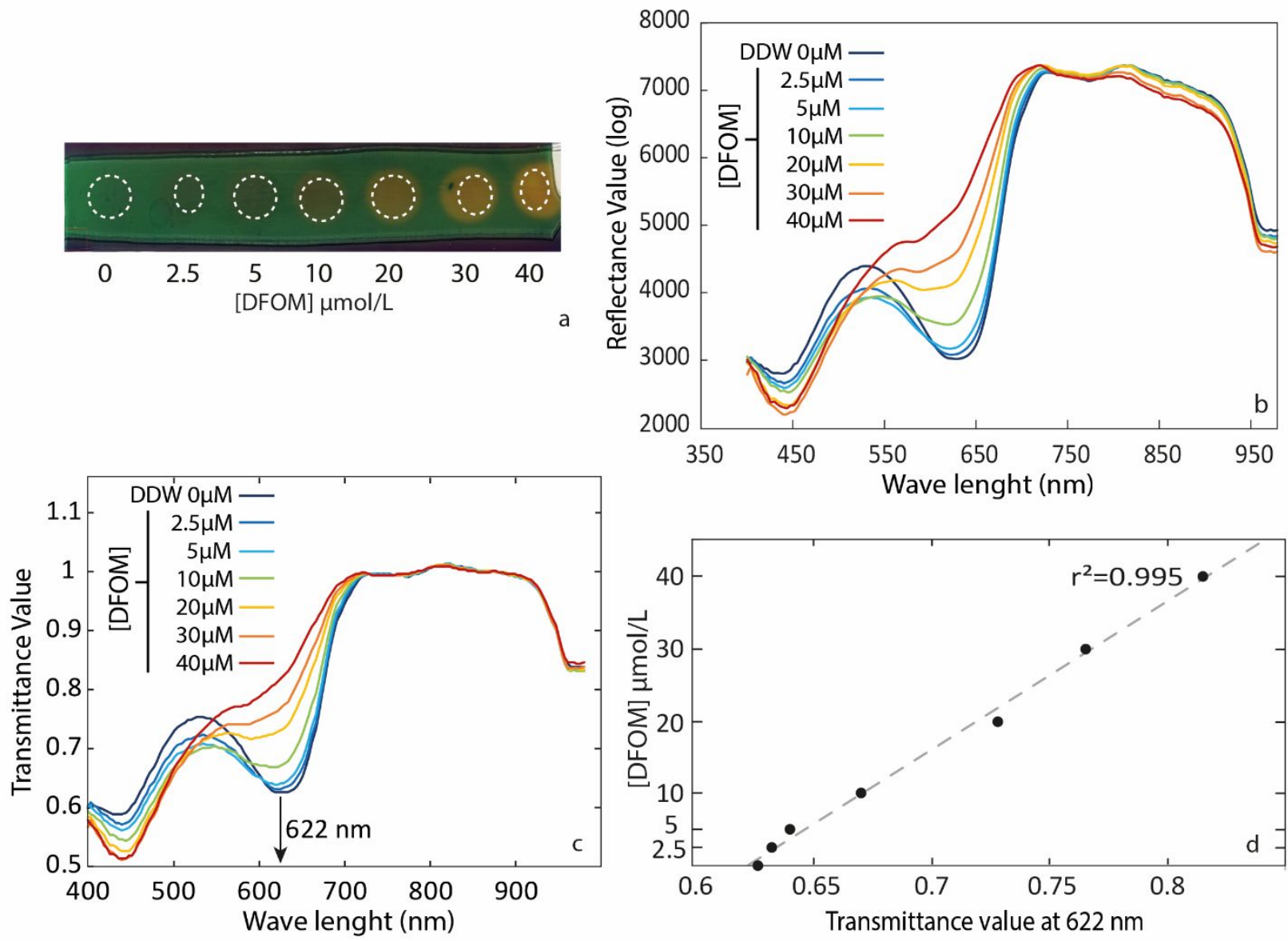

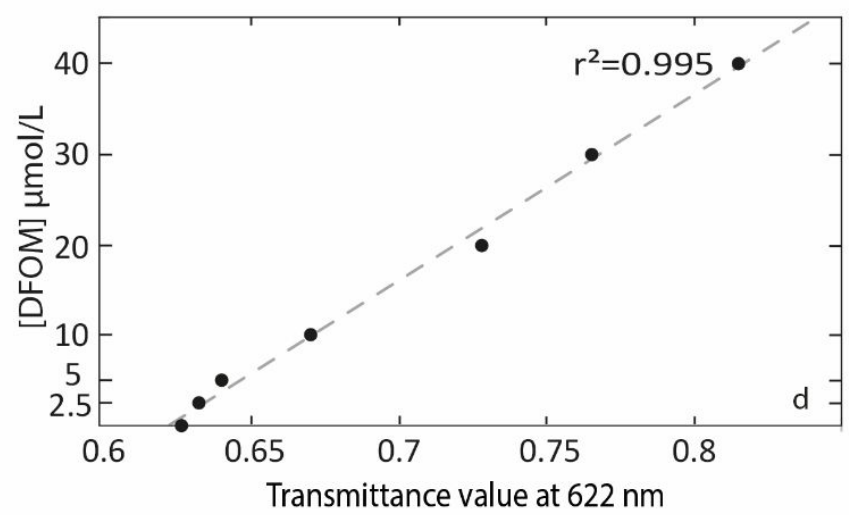

Figure 4: Colorimetric calibration. a. Image of assembled DFOM calibration and reagent gels. Dashed lines represent the ROI (Region of interest) selected for image treatments. b. Mean reflectance spectra obtained from each ROI. c. Transmittance spectra calculated from the previous reflectance spectra assuming a flat background given by a regression line in the 720 $920 \mathrm{~nm}$ spectral range. d. Transfer function obtained from the maximum transmittance signal $(622 \mathrm{~nm})$ and the siderophore (DFOM) concentration.

$\mathrm{PO}_{4}{ }^{3-}$ interference assessment. As described above, plant experiments conducted in the agar growth media were performed using a modified Hoagland nutritive solution in order to avoid any potential interference of dissolved phosphate that is as concentrated as $1 \mathrm{mmol} / \mathrm{L}$ in the usual Hoagland solution ${ }^{64}$. In order to open the application of the DET-CAS device to natural 
environments, we tested the interference of phosphate that covers a classic range of concentration found in pore-waters from soils or sediments (up to $100-200 \mu \mathrm{mol} / \mathrm{L}$ in marine sediment pore-water ${ }^{65,66}$, and up to $100 \mu \mathrm{mol} / \mathrm{L}$ in soil pore-water ${ }^{67-69}$ ). A range of $\mathrm{K}_{2} \mathrm{HPO}_{4}$ solutions was prepared from 25 to $300 \mu \mathrm{mol} / \mathrm{L}$ and equilibrated with a gel following the same image acquisition and treatment than for the DFOM calibration. We obtained reflectance spectra without any observable decrease at the absorbance value of $622 \mathrm{~nm}$ (Figure S2) allowing the application of the CAS-DET device in natural environments.

Experimental application. Figure 5 shows for the first time the distribution of siderophores that were produced around the root web under different conditions for two plants: sunflower (H. annuus, E1 and E2) and wheat (T. aestivum, E3 and E4), grown in Petri dishes within an agar medium.

Sunflower experiments. Treated images do not significantly detect the presence of siderophores in the experiment E1. Under iron stress $H$. annuus lowers the $\mathrm{pH}$ of the nutrient solution to increase the rate of the iron uptake but does not produce any iron-ligands ${ }^{70,71}$. Consequently, in absence of siderophore microbial producers, it was expected to have a freesiderophore environment. This result confirms that our culturing medium as well as the root exudates does not interfere with the reagent to create a false positive result. In experiment E2, the presence of siderophores is slightly visible on the edge of the culturing medium but remains close to the injection spots of $P$. fluorescens.

Wheat experiments. In the experiment E3, we were able to detect siderophores centered around the main root of the system. Because this experiment was performed without any addition of siderophore microbial producers, we demonstrated here the capability of our device to detect the natural production of iron-ligands produced by the wheat roots. Although our method does 
not allow identification of the nature of iron-ligands, it is reasonable to suggest that the ironligands detected here were phytosiderophores. Indeed, T. aestivum is well known to naturally produce phytosiderophores in free-iron environments especially during the first stage of growth $^{39,58-60}$. As shown here, this method allowed to precisely locate the main area where phytosiderophores were produced.

In experiment E4, we clearly documented a strong production of siderophores along the sites where the bacterial solution was inoculated, with a maximum concentration reached at the vicinity of the dense root web. Surprisingly, for both experiments, the siderophore concentrations were higher than the maximum of $40 \mu \mathrm{mol} / \mathrm{L}$ as set up for the calibration curve. Obviously such high concentrations are not representative of natural environments, as we will discuss later, however it allows us to validate the use of this technique by successfully providing a 2D map of the siderophore sites of production from both plants and bacteria. 
Experiment E1 : $H$. annuus $+0 P$. fluorescens
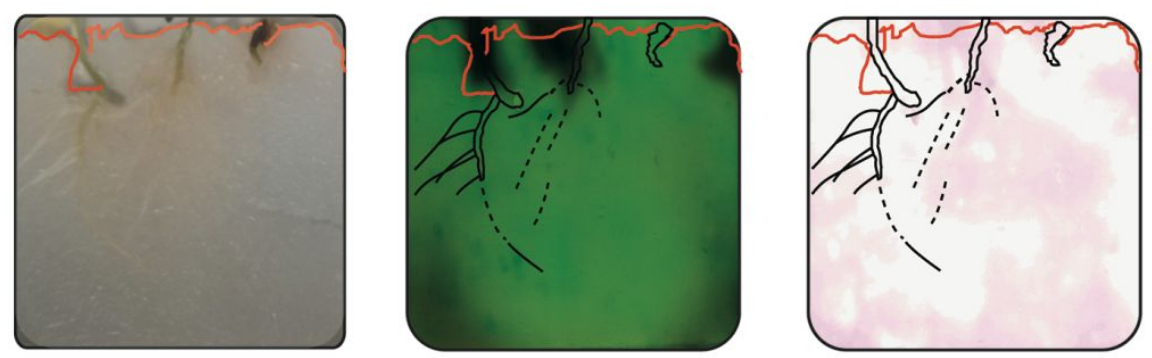

Experiment E2: $H$. annuus $+P$. fluorescens
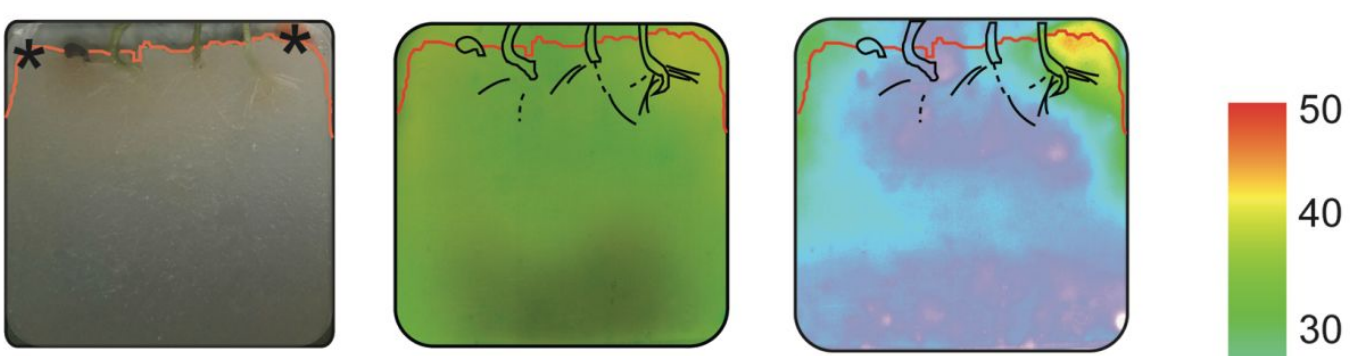

Experiment E3: T. aestivum + OP. fluorescens
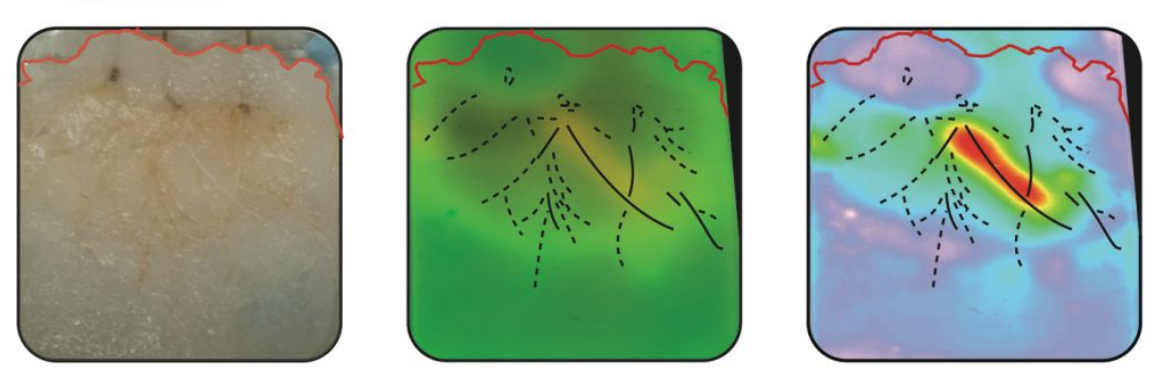

0

$\mu \mathrm{mol} / \mathrm{L}$

Experiment E4: T. aestivum $+P$. fluorescens

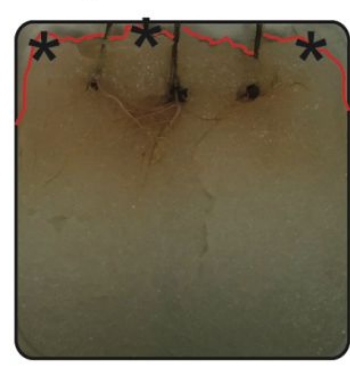

Culture medium

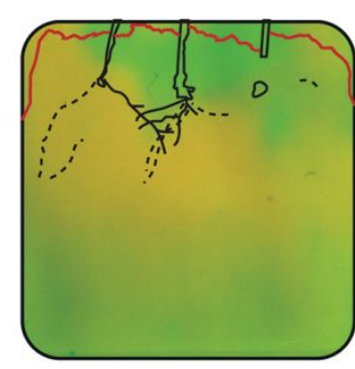

Transmittance

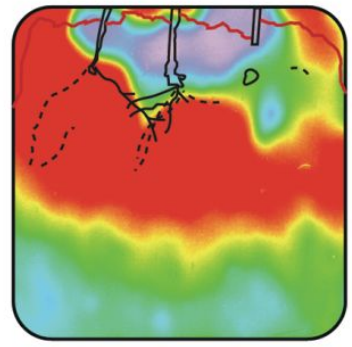

Concentration

Figure 5: Experiments on iron-free agar plates. Stars symbolize the $P$. fluorescens inoculation spots. The surface of the agar medium gel is delineated by the red line (note that the agar expanded further up during the contact with the CAS-DET device). The roots are indicated on the gel images by plain dark lines when the roots were at the surface of the agar plate (i.e. in 
direct contact of the gel probe) and with dashed lines when they were deeper within the agar medium. From left to right we present the agar plates' pictures, the transmittance images of the gels at $622 \mathrm{~nm}$ and then the images converted into concentrations.

Plant experiments comparison. For both experiments E2 and E4 (inoculation with $P$. fluorescens), the concentration of siderophores was detected and quantified but respective 2D distribution was very different with a very intense siderophore production for wheat after inoculation. Two non-exclusive explanations can be argued to explain such a difference between wheat and sunflower experiments: (i) P fluorescens does not survive well and/or only produces small amounts of siderophores per bacterial cell in the sunflower rhizosphere because plant exudates are not adequate for its growth and/or its siderophore production, and overall it results in a low production of siderophores. (ii) On the contrary, the wheat rhizosphere is known to host and favor the growth of $P$. fluorescens ${ }^{72-75}$. The capability of the wheat to offer a favorable environment to $P$. fluorescens allows bacteria to successfully grow and to produce siderophores. The high concentration of siderophores measured in the wheat root system E4 results from the $P$. fluorescens siderophores and, possibly in addition, from the phytosiderophore production (experiment E3). It was shown in the literature that the presence of $P$. fluorescens can enhance the production of siderophore by the plant itself (i.e. phytosiderophores) in the wheat rhizosphere ${ }^{76}$.

The concentrations obtained from experiments E3 and E4 reached $50 \mu \mathrm{mol} / \mathrm{L}$ which is in accordance with previous studies performed with the soil solutions and/or from the total root exudates $^{39,77,78}$. Additionally, the CAS-DET technique allows to quantify the concentration of siderophores and to locate their production hot-spots. For example, in experiment E3 the 
production is strongly concentrated in a small area around a root at the edge of the culture medium. We can also see a more diffuse distribution of the siderophores where the roots are deeper within the medium. The CAS-DET device gives new insights to better understand the production pattern of siderophores in the rhizosphere as it allows: (i) clear identification of the area of production, (ii) to quantify the in situ production. However, we are aware that our 0-iron environments maintained during 10 days are not representative of a natural environment and clearly enhance the capability of both bacteria and plants to produce siderophores in high quantity as shown in previous studies ${ }^{39,79}$. Nevertheless, these results allow us to fully validate the use of this technique as a non-destructive tool to quantify and map in $2 \mathrm{D}$ the siderophore production in the rhizosphere.

Recommendations for natural environments applications. In natural environments some factors can influence the diffusion of siderophores into the probe such as the tortuosity of the soil, the temperature, and the ionic strength of the pore-water. A lower temperature, a strong tortuosity and strong ionic strength are factors than can delay the diffusion of siderophores towards the probe. As shown for other DET devices, those factors lead to higher equilibration time, up to $5 \mathrm{~h}$, between the environment and the gel probe ${ }^{42,80}$. A higher equilibrium time may lead to a loss of spatial resolution due to lateral diffusion within the gel probe. However, the device will still be able to locate at the precision of the pixel the site of siderophore production and diffusion modelling may help at reconstructing in situ chemical gradients ${ }^{44}$.

The CAS-DET device allows the detection of all the ligands with higher affinity for iron than the CAS ligand. Therefore, we recommend to use this CAS-DET device in combination with a DET iron-phosphate probe which is able to detect both free iron and phosphate ${ }^{41}$. This second probe will control the amount of free-phosphate in the environment preventing false interpretations of 
the CAS-DET results due to potential high concentration $\mathrm{PO}_{4}{ }^{3-}$ hotspots. In addition this DET probe allows quantification of the total amount of iron in pore-waters ${ }^{41,81}$. The combination of the two probes will allow to better understand siderophore spatial distribution in the context of iron bioavailability and nutrients uptake.

\section{Conclusion}

The results obtained in this study clearly demonstrate the capability of the CAS-DET device to map the siderophores in artificial environment such as agar medium, and, combined with the use of the hyperspectral imaging, to quantify them at micro-molar scale. We are confident that this device is also suitable for deployment in environments such as natural soils where high spatial heterogeneity and siderophore distribution as hotspots along roots is expected. This technique combined with other DET probes that are able to detect dissolved iron, phosphate ${ }^{41,81}$ or manganese, can provide a powerful tool to assess free and complexed metal distribution in the environments. Therefore, the combined use of different DET probes along with our device will give a great opportunity to investigate the trace metal transfer from soil to plants to understand fundamental mechanisms as well as for more applied objectives such as phytoextraction.

\section{Supporting Information:}

Two figures are shown in supporting information regarding $\mathrm{pH}$ and $\mathrm{PO}_{4}{ }^{3-}$ concentrations under which our CAS assay can be used.

\section{Acknowledgments:}


This study was financed by France's Pays de la Loire Regional Council (under the POLLUSOLS-OSUNA Project). The authors are most grateful to Manuel Giraud for his great help with the hyperspectral camera. We also thank Sophie Quinchard, Anthony Barbe, Brieuc Thibault de Chanvalon and Thierry Jauffrais for their help in the lab and all the LPG-BIAF staff for their support. Thanks for the anonymous reviewers for their constructive suggestions. 


\section{References}

(1) Schwyn, B.; Neidlands, J. B. Anal. Biochem. 1987, 160, 47-56.

(2) Neilands, J. B. Methodology of siderophores 1984, ed.; Springer Berlin Heidelberg: Berlin, Heidelberg; Vol. 58, p 1-24.

(3) Renshaw, J. C.; Robson, G. D.; Trinci, A. P. J.; Wiebe, M. G.; Livens, F. R.; Collison, D.; Taylor, R. J. Mycol. Res. 2002, 106 (10), 1123-1142.

(4) Kraemer, S. M.; Crowley, D. E.; Kretzschmar, R. Geochemical Aspects of Phytosiderophore-Promoted Iron Acquisition by Plants 2006, ed.; Academic Press; Vol. 91, p 1-46.

(5) Cornelis, P. Appl. Microbiol. Biotechnol. 2010, 86 (6), 1637-1645.

(6) Ahmed, E.; Holmström, S. J. M. Microb. Biotechnol. 2014, 7 (3), 196-208.

(7) Neilands, J. B. Iron and its role in microbial physiology 1974, ed.; Academic Press; Vol., p 3-34.

(8) Emery, T. H. The storage and transport of iron. 1978, ed.; Marcel Dekker: New York; Vol. 7, p 77-126.

(9) Kraemer, S. M. Aquat. Sci. 2004, 66 (1), 3-18.

(10) Stintzi, A.; Barnes, C.; Xu, J.; Raymond, K. N. Proc. Natl. Acad. Sci. 2000, 97 (20), 10691-10696.

(11) Barbeau, K.; Rue, E. L.; Bruland, K. W.; Butler, A. Nature 2001, 413, 409.

(12) Boyd, P. W.; Jickells, T.; Law, C. S.; Blain, S.; Boyle, E. A.; Buesseler, K. O.; Coale, K. H.; Cullen, J. J.; de Baar, H. J.; Follows, M.; Harvey, M.; Lancelot, C.; Levasseur, M.; Owens, N. P.; Pollard, R.; Rivkin, R. B.; Sarmiento, J.; Schoemann, V.; Smetacek, V.; Takeda, S.; Tsuda, A.; Turner, S.; Watson, A. J. Science 2007, 315 (5812), 612-617.

(13) Kalinowski, B. E.; Liermann, L. J.; Brantley, S. L.; Barnes, A.; Pantano, C. G. Geochim. Cosmochim. Acta 2000, 64 (8), 1331-1343.

(14) Hiradate, S.; Inoue, K. J. Soil Sci. Plant Nutr. 1998, 44 (3), 305-313.

(15) Puschenreiter, M.; Gruber, B.; Wenzel, W. W.; Schindlegger, Y.; Hann, S.; Spangl, B.; Schenkeveld, W. D. C.; Kraemer, S. M.; Oburger, E. Environ. Exp. Bot. 2017, 138, 67-76.

(16) Schalk, I. J.; Hannauer, M.; Braud, A. Environ. Microbiol. 2011, 13 (11), 2844-2854.

(17) Bellenger, J. P.; Wichard, T.; Kustka, A. B.; Kraepiel, A. M. L. Nat. Geosci. 2008, 1, 243.

(18) Braud, A.; Hoegy, F.; Jezequel, K.; Lebeau, T.; Schalk, I. J. Environ. Microbiol. 2009, 11 (5), 10791091.

(19) Schenkeveld, W. D. C.; Oburger, E.; Gruber, B.; Schindlegger, Y.; Hann, S.; Puschenreiter, M.; Kraemer, S. M. Plant Soil. 2014, 383 (1-2), 59-71.

(20) Kraemer, S. M.; Duckworth, O. W.; Harrington, J. M.; Schenkeveld, W. D. C. Aquat. Geochem. 2015, 21 (2), 159-195.

(21) Kustka, A. B.; Jones, B. M.; Hatta, M.; Field, M. P.; Milligan, A. J. Mar. Chem. 2015, 173, 195-207.

(22) Sorichetti, R. J.; Creed, I. F.; Trick, C. G. Freshwater Biol. 2014, 59 (4), 679-691.

(23) Kloepper, J. W.; Leong, J.; Teintze, M.; Schroth, M. N. Curr. Microbiol. 1980, 4 (5), 317-320.

(24) Robin, A.; Vansuyt, G.; Hinsinger, P.; Meyer, J. M.; Briat, J.-F.; Lemanceau, P. Iron dynamics in the rhizosphere : consequences for plant health and nutrition 2008, ed.; Academic Press, San Diego (EtatsUnis); Vol. 99, p 183-225.

(25) Schroth, M. N.; Hancock, J. G. Science 1982, 216 (4553), 1376-1381.

(26) Wichard, T.; Bellenger, J.-P.; Loison, A.; Kraepiel, A. M. L. Environ. Sci. Technol. 2008, 42 (7), 24082413.

(27) Rajkumar, M.; Ae, N.; Prasad, M. N. V.; Freitas, H. Trends Biotechnol. 2009, 28 (3), 142-149.

(28) Lebeau, T.; Braud, A.; Jézéquel, K. Environ. Pollut. 2008, 153 (3), 497-522.

(29) Essén, S. A.; Bylund, D.; Holmström, S. J. M.; Moberg, M.; Lundström, U. S. BioMetals 2006, 19 (3), 269-282.

(30) Holmström, S. J. M.; Lundström, U. S.; Finlay, R. D.; van Hees, P. A. W. Biogeochemistry 2004, 71 (2), 247-258. 
(31) Mawji, E.; Gledhill, M.; Milton, J. A.; Tarran, G. A.; Ussher, S.; Thompson, A.; Wolff, G. A.; Worsfold, P. J.; Achterberg, E. P. Environ. Sci. Technol. 2008, 42 (23), 8675-8680.

(32) Macrellis, H. M.; Trick, C. G.; Rue, E. L.; Smith, G.; Bruland, K. W. Mar. Chem. 2001, 76, 175-187.

(33) Velasquez, I.; Nunn, B. L.; Ibisanmi, E.; Goodlett, D. R.; Hunter, K. A.; Sander, S. G. Mar. Chem. 2011, 126 (1), 97-107.

(34) Crowley, D. E.; Römheld, V.; Marschner, H.; Szaniszlo, P. J. Plant Soil 1992, 142 (1), 1-7.

(35) Römheld, V.; Marschner, H. Plant Physiol. 1986, 80 (1), 175-180.

(36) Gries, D.; Brunn, S.; Crowley, D. E.; Parker, D. R. Plant Soil 1995, 172 (2), 299-308.

(37) Takagi, S. i.; Nomoto, K.; Takemoto, T. J. Plant. Nutr. 1984, 7 (1-5), 469-477.

(38) Crowley, D. E.; Wu, C. L.; Gries, D.; Brünn, S.; Parker, D. R. Plant Soil 2002, 241 (1), 57-65.

(39) Oburger, E.; Gruber, B.; Schindlegger, Y.; Schenkeveld, W. D. C.; Hann, S.; Kraemer, S. M.; Wenzel, W. W.; Puschenreiter, M. New Phytol. 2014, 203 (4), 1161-1174.

(40) Jézéquel, D.; Brayner, R.; Metzger, E.; Viollier, E.; Prévot, F.; Fiévet, F. Estuar. Coast. Shelf Sci. 2007, $72(3), 420-431$.

(41) Cesbron, F.; Metzger, E.; Launeau, P.; Deflandre, B.; Delgard, M.-L.; Thibault de Chanvalon, A.; Geslin, E.; Anschutz, P.; Jézéquel, D. Environ. Sci. Technol. 2014, 48 (5), 2816-2826.

(42) Pagès, A.; Teasdale, P. R.; Robertson, D.; Bennett, W. W.; Schäfer, J.; Welsh, D. T. Chemosphere 2011, 85 (8), 1256-1261.

(43) Robertson, D.; Teasdale, P. R.; Welsh, D. T. Limnol. Oceanogr. Methods 2008, 6 (10), 502-512.

(44) Metzger, E.; Thibault de Chanvalon, A.; Cesbron, F.; Barbe, A.; Launeau, P.; Jézéquel, D.; Mouret, A. Environ. Sci. Technol. 2016, 50 (15), 8188-8195.

(45) Davison, W.; Grime, G. W.; Morgan, J. A. W.; Clarke, K. Nature 1991, 352, 323.

(46) Andrews, M. Y.; Santelli, C. M.; Duckworth, O. W. 2016, 6, 890-898.

(47) Langmyhr, F. J.; Klausen, K. S. Anal. Chim. Acta 1963, 29, 149-167.

(48) Andrews, M. Y.; Duckworth, O. BioMetals 2016, 29 (6), 1085-1095.

(49) Louden, B. C.; Haarmann, D.; Lynne, A. M. J Microbiol Biol Educ. 2011, 51-53.

(50) Machuca, A.; Milagres, A. M. F. Lett. Appl. Microbiol. 2003, 36 (3), 177-181.

(51) Zhang, H.; Davison, W. Anal. Chim. Acta 1999, 398 (2), 329-340.

(52) Neilands, J. B. Annu. Rev. Biochem. 1981, 50, 715-731.

(53) Lillesaeter, O. Remote Sens. Environ. 1982, 12 (3), 247-254.

(54) Miller, J. R.; Steven, M. D.; Demetriades-Shah, T. H. Int. J. Remote Sens. 1992, 13 (17), 3273-3286.

(55) Kazemipour, F.; Launeau, P.; Méléder, V. Remote Sens. Environ. 2012, 127, 1-13.

(56) Kazemipour, F.; Meleder, V.; Launeau, P. J. Quant. Spectrosc. Radiat. Transf. 2011, 112 (1), 131-142.

(57) Launeau, P.; Méléder, V.; Verpoorter, C.; Barillé, L.; Kazemipour-Ricci, F.; Giraud, M.; Jesus, B.; Le Menn, E. Remote Sens. 2018, 10 (5), 716.

(58) Tolay, I.; Erenoglu, B.; Römheld, V.; Braun, H. J.; Cakmak, I. J. Exp. Bot. 2001, 52 (358), 1093-1099.

(59) Reichman, S. M.; Parker, D. R. New Phytol. 2007, 174 (1), 101-108.

(60) Zhang, F.-S.; Römheld, V.; Marschner, H. Soil Sci. Plant Nutr. 1991, 37 (4), 671-678.

(61) Trapet, P.; Avoscan, L.; Klinquer, A.; Pateyron, S.; Citerne, S.; Chervin, C.; Mazurier, S.; Lemanceau, P.; Wendehenne, D.; Besson-Bard, A. Plant Physiol. 2016, 17 (1), 675-693.

(62) Meyer, J. M.; Abdallah, M. A. Microbiology 1978, 107, 319-328.

(63) Albrecht-Gary, A.-M.; Blanc, S.; Rochel, N.; Ocaktan, A. Z.; Abdallah, M. A. Inorg. Chem. 1994, 33

(26), 6391-6402.

(64) Hoagland, D. R.; Arnon, D. I. California Agricultural Experiment Station 1950, Circular-347.

(65) Slomp, C. P.; Mort, H. P.; Jilbert, T.; Reed, D. C.; Gustafsson, B. G.; Wolthers, M. 2013, 8 (4), e62386.

(66) Sundby, B.; Gobeil, C.; Silverberg, N.; Mucci, A. Limnol. Oceanogr. 1992, 37 (6), 1129-1145.

(67) Negrin, V. L.; Spetter, C. V.; Asteasuain, R. O.; Perillo, G. M. E.; Marcovecchio, J. E. 2011, 23 (2), $212-$ 221. 
(68) Lamb, D. T.; Kader, M.; Wang, L.; Choppala, G.; Rahman, M. M.; Megharaj, M.; Naidu, R. 2016, 50 (23), 13062-13069.

(69) Sigua, G. C.; Stone, K. C.; Bauer, P. J.; Szogi, A. A.; Shumaker, P. D. 2017, 186, 75-85.

(70) Römheld, V.; Marschner, H. Fine regulation of iron uptake by the Fe-efficient plant Helianthus annuus 1979, ed.; Academic Press: London; Vol., p 405-417.

(71) Kashirad, A.; Marschner, H. Plant Soil 1974, 41 (1), 91-101.

(72) Dijkstra, A. F.; Scholten, G. H. N.; van Veen, J. A. Biol. Fertility Soils 1987, 4 (1), 41-46.

(73) Behn, O. J. Plant. Dis. Prot. 2008, 115 (1), 4-8.

(74) Chapon, A.; Guillerm, A.-Y.; Delalande, L.; Lebreton, L.; Sarniguet, A. Eur. J. Plant Pathol. 2002, 108 (5), 449-459.

(75) Weller, D. M.; Cook, R. J. Phytopathology 1983, 73, 463-469.

(76) Abbas-Zadeh, P.; Saleh-Rastin, N.; Asadi-Rahmani, H.; Khavazi, K.; Soltani, A.; Shoary-Nejati, A. R.; Miransari, M. Acta Physiol. Plant 2010, 32 (2), 281-288.

(77) Römheld, V. Plant Soil 1991, 130 (1), 127-134.

(78) Shi, W.-M.; Chino, M.; Youssef, R. A.; Mori, S.; Takagi, S. Soil Sci. Plant Nutr. 1988, 34 (4), 585-592.

(79) Nozoye, T.; Nagasaka, S.; Kobayashi, T.; Takahashi, M.; Sato, Y.; Sato, Y.; Uozumi, N.; Nakanishi, H.; Nishizawa, N. K. J. Biol. Chem. 2011, 286 (7), 5446-5454.

(80) Pagès, A.; Welsh, D. T.; Robertson, D.; Panther, J. G.; Schäfer, J.; Tomlinson, R. B.; Teasdale, P. R. Estuar. Coast. Mar. Sci. 2012, 115, 282-290.

(81) Thibault de Chanvalon, A.; Metzger, E.; Mouret, A.; Knoery, J.; Geslin, E.; Meysman, F. J. R. Mar. Chem. 2017, 191, 34-49. 

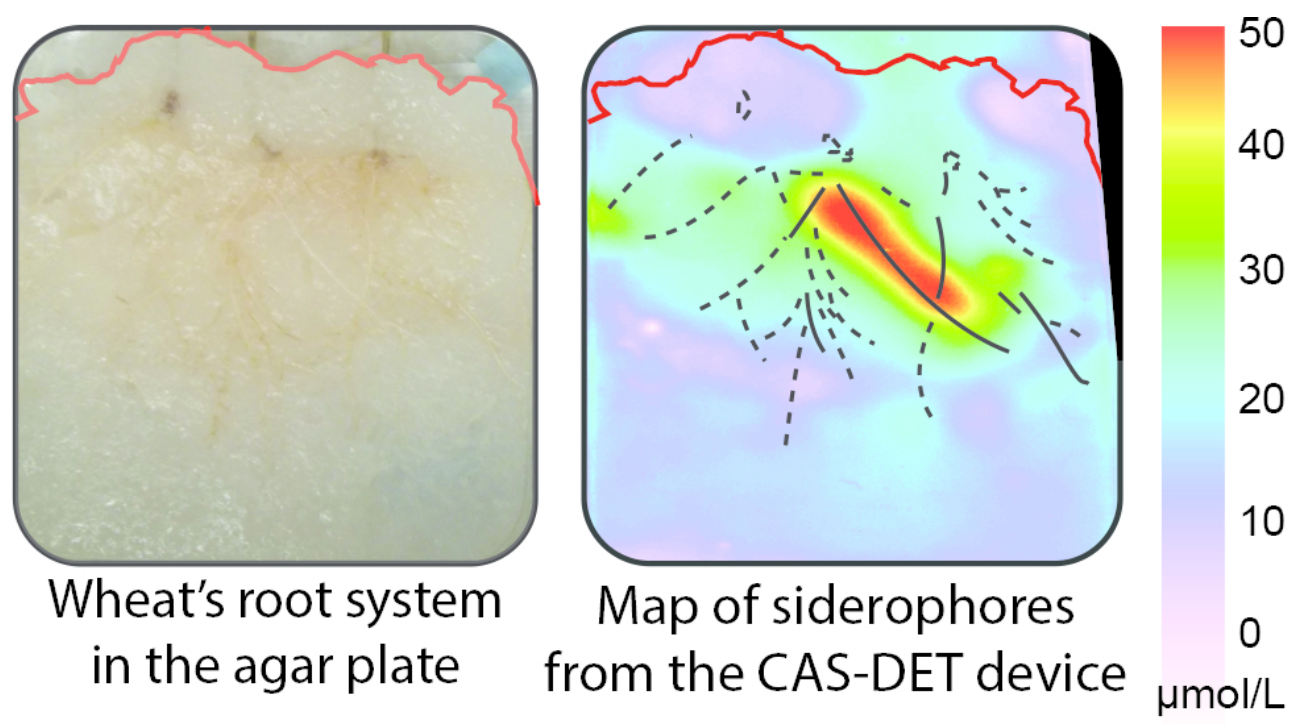

TOC graphic 